\title{
Pattern of Conidial Discharge of an Entomophthora species ("grylli" type) (Entomophthorales : Entomophthoraceae) from Infected Cadavers of Mamestra brassicae L. (Lepidoptera : Noctuidae $)^{1}$
}

\author{
Joji AoKI \\ Faculty of Agriculture, Tokyo University of Agriculture and Technology, 3-5-8, \\ Saiwai-cho, Fuchu, Tokyo 183, Japan
}

(Received January 20, 1981)

\begin{abstract}
The patterns of conidial discharges of an Entomophthora species ("grylli" type) were investigated on naturally-infected larval cadavers of Mamestra brassicae under continuous dark or light conditions at $20^{\circ} \mathrm{C}$, and in the field. The great majority of the infected larvae in a field of carrots were killed in the afternoon and a few at night. The longest lag period in advance of conidial discharge occurred with cadavers collected at 2 a.m. The lag period decreased during the course of the day and was shortest on cadavers collected at 10 p.m. The fungus, by adjusting the length of the lag period, discharged most of the conidia during the night from the cadavers collected during the day. The conidial discharge was initiated rapidly at night on cadavers that had been collected in the evening and night. However, the initiation of the conidial discharge was delayed and continued for a long period on cadavers collected at 2 a.m. ; many conidia continued to be discharged the following night. The patterns of the conidial discharges in a day were similar under the above three different conditions.
\end{abstract}

\section{INTRODUGTION}

Entomophthorous fungi cause severe epizootics in high density populations of numerous insect species. Species of Entomophthoraceae have some unique aspects when compared with other entomopathogenic fungi. One of most characteristic differences is the mode of conidial discharge. The turgid conidial cells, which were produced by conidiophores on the external surface of an infected insect, are suddenly rounded-off, and they are shot to a distance of several centimeters. The discharged conidia form an aureole arround the dead insect. This characteristic property is very important in understanding the development of epizootics in insect populations by entomophthorous fungi.

The method of conidial discharge in entomophthorous fungi is generally known. However, few reports have analyzed quantitatively the pattern of the conidial discharge. An epizootic caused by an Entomophthora species of the "grylli" type developed in a population of Mamestra brassicae larvae in a field of carrots in October, 1977.

1 This research was supported in part by Grant-in-Aid for Scientific Research from The Ministry of Education, Science and Culture, Japan (Grant No. 556031). 
The pattern of the conidial discharges on the infected larval cadavers was investigated, and the results of this study are reported at this time.

\section{MATERIALS AND METHODS}

The experimental plot was located in a $600-\mathrm{m}^{2}$ field of carrots planted at the Tokyo University of Agriculture and Technology in Fuchu, Tokyo. The carrots were planted in 0.8-m rows and averaged 30 plants $/ \mathrm{m}^{2}$. Most of the Mamestra brassicae larvae killed naturally by the Entomophthora species of "grylli" type had climbed to the upper parts of the host plants before dying. The killed larvae were collected thoroughly from 6 rows $(30 \times 0.8 \mathrm{~m})$.

Prior to the start of the experiment, all of the larval cadavers which had been killed were removed from test rows. Subsequently, the cadavers which had been killed within 4-hr were collected 7 times at 4 -hr intervals from 10 a.m. to the following $10 \mathrm{a} . \mathrm{m}$. Since each collecting operation took approximately $30-\mathrm{min}$, the operation was started 30 -min before the assigned time. There is the likelihood that some collected larvae died during the operation.

Immediately after collection, each cadaver was taped at both ends with a narrow celophane tape to the underside of a Petri-dish cover measuring $12 \mathrm{~cm}$ in diameter. The bottom of the dish was covered with a moistened filter paper, and a glass slide was placed on the paper. A thin transparent cover glass $(18 \times 18 \mathrm{~mm})$ was placed on the slide directly beneath the cadaver. The Petri-dishes were divided into 3 groups and held under the following conditions : (1) continuous darkness, (2) continuous light, and (3) natural field condition. The first group was kept in complete darkness in a dark room. The dishes were manipulated when necessary under safety light (A Toshiba safety lamp for photography). The second group was illuminated continuously with four 40-watt cool-white fluorescent lamps (300-lux measured with a Megatron light meter, Type 22). The Petri-dishes of each group were kept in separate temperature controlled rooms at $20^{\circ} \mathrm{C} \pm 1$. The third group was kept outdoors in the shade. The conidia were allowed to fall onto the sampling cover glass for 2-hr, and then the glass was exchanged with a new one every $2-\mathrm{hr}$ in order to continuously collect the discharged conidia. The treatments were maintained for 52-hr from the beginning of the incubation of the larval cadavers.

The exposed cover glass was transferred to a Petri-dish which had been filled with formaldehyde gas, and held for 30-min to fix the conidia. After fixation, the number of conidia deposited on the cover glass was counted under a microscope in 10 fields of vision at $100 \mathrm{X}$ magnification. When a great number of the conidia were deposited on the cover glass, the counting was conducted in 10 fields at $400 \mathrm{X}$ magnification, and the number counted was increased sixteenfold.

The cadavers were collected and tested at 10 a.m., 2 p.m., 6 p.m., 10 p.m., 2 a.m., 6 a.m., and 10 a.m. the following day. All cadavers collected during these periods were tested. The number of cadavers collected and tested from $10 \mathrm{a} . \mathrm{m}$. to 10 a.m. the following day was as follows : 2, 8, 7, 3, 1, 1, and 3 under dark condition ; $1,8,6,3,1,0$, and 3 under light condition; and 1,8,6,2,1, 1, and 2 in the field. When more than one cadaver was tested under the same period and condition, the average number of conidia per cadaver was calculated. Since only 2 cadavers could be collected at 6 a.m., a test under dark condition at 6 a.m. was omitted. 


\section{RESULTS}

Variations in numbers of killed larvae throughout the day

The number of infected cadavers obtained at each collection period is shown in Fig. 1. The majority of the killed larvae was observed at 2 and 6 p.m. Subsequently, the number decreased gradually from nightfall to the peep of dawn and then increased in forenoon.

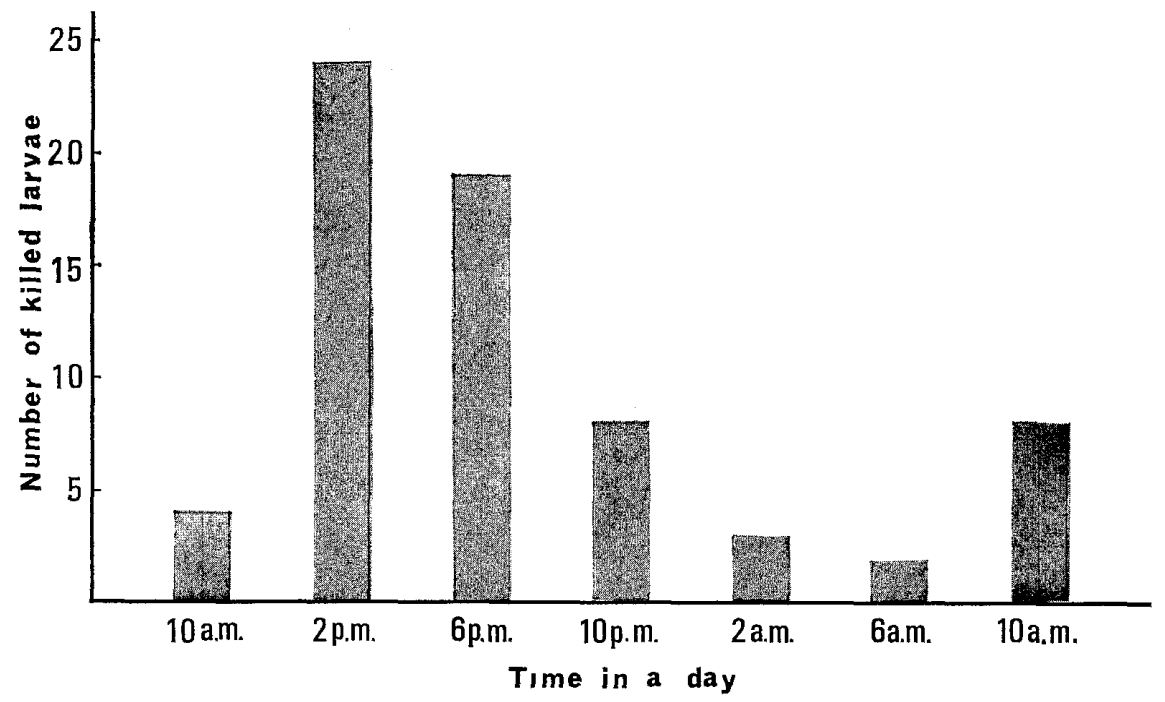

Fig. 1. Numbers of Mamestra brassicae larvae killed during a day by an Entomophthora species of "grylli" type in a field of carrots.

\section{Conidial discharge under continuous dark condition}

The periodic discharge of conidia in all treatments are given in Fig. 2. Initial lag periods of 4 to 8-hr durations occurred in advance of the conidial discharge.

In general, with the exception of the cadaver collected at 2 a.m., the conidia that formed on the cadavers were discharged rapidly in large numbers, and were at a peak of discharge in a short time after incubation in the dish. Subsequently, the number of discharged conidia gradually decreased with the lapse of time to zero before 44-hr after the incubation of the cadavers in the dishes. The conidial discharge on the cadaver collected at 2 a.m. was sparse at first and reached its peak after 26-hr, and thus formed a flattened graph (Fig. 2). The total number of discharged conidia varied with the size of the cadavers.

Remarkably rapid discharges of conidia occurred on cadavers collected at 6 and 10 p.m. In these cases, the conidial discharge began within 4-hr, and a great majority of the conidia were discharged during the night in particular with cadavers collected at 6 p.m. In cadavers collected at 10 p.m., a portion of the conidia were already discharged by the early morning hours. Even though the discharge continued during the day, a considerabl number of conidia were still discharged the following night. The cadavers collected at 2 p.m. were obtained in the greatest numbers and the conidial discharge was initiated after 6-hr incubation and about half of the total conidia were discharged during the night. There was a 8 to $10-\mathrm{hr}$ lag period on cadavers collected at 10 a.m., and the conidial discharge therefore was in- 


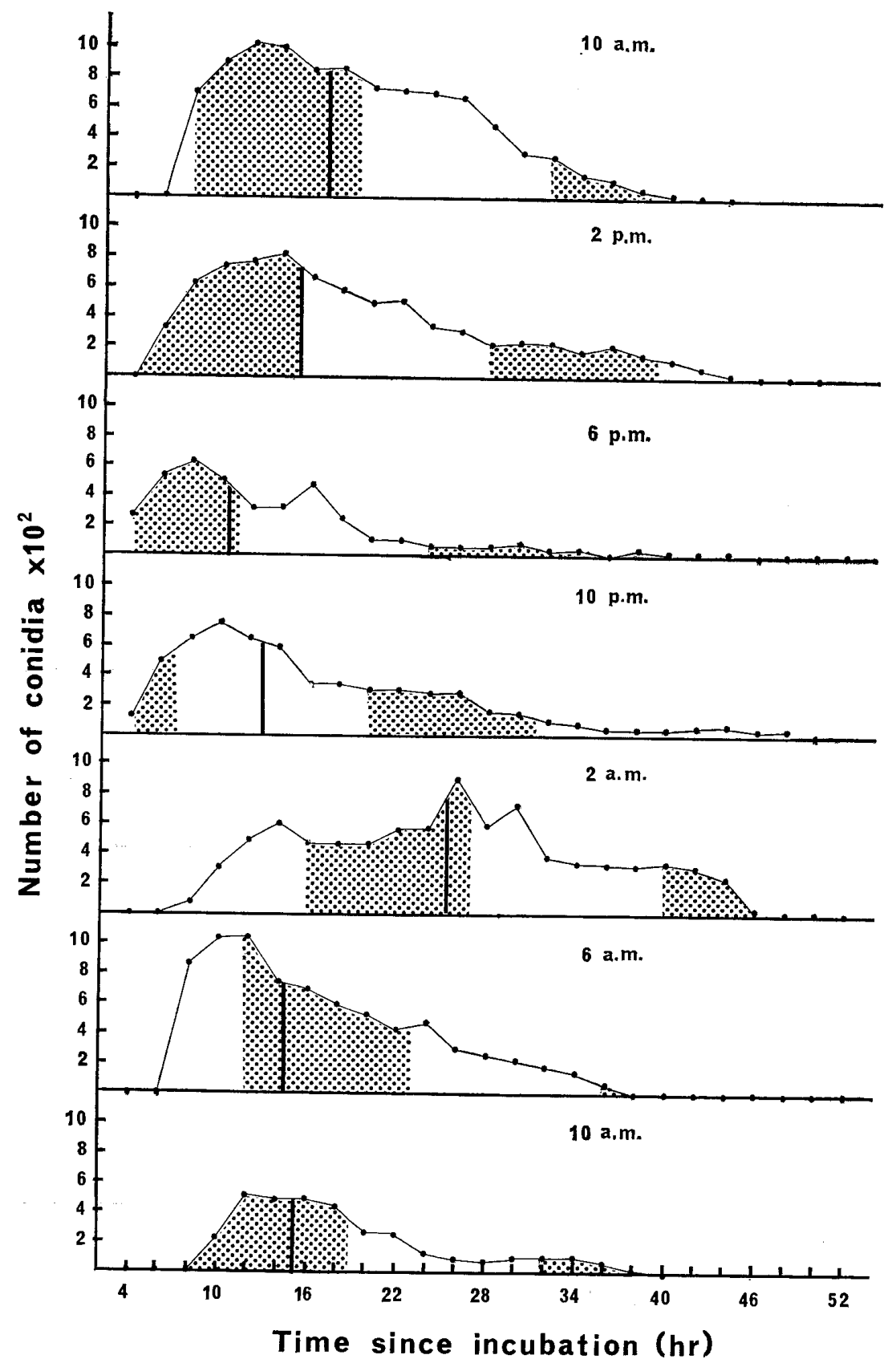

Fig. 2. Patterns of conidial discharges of an Entomophthora species of "grylli" type from infected cadavers of Mamestra brassicae larvae incubated under a continuous dark condition at $20^{\circ} \mathrm{C}$. Each point represents the mean of at least 10 counts from each cadaver. Vertical bar in each graph indicates the time at which half of the total conidia had been discharged. Shaded areas represent the periods from sunset (ca. $5: 06$ p.m.) to sunrise (ca. 5 : 47 a.m.).

itiated just after sunset with about half of the conidia being discharged as in the case of cadavers collected at 2 p.m. In the cadaver collected at 6 a.m., the conidial discharge began in the late afternoon and continued during the night. In the cadaver collected at 2 a.m., a small number of conidia were discharged at 10 a.m., and a slow 
increase in discharge continued from daylight to the following night, and finally the discharge reached its peak at 4 a.m. the next morning.

\section{Conidial discharge under continuous light condition}

The discharge of conidia under continuous light condition in all treatments are given in Fig. 3. There were lag periods that ranged between 4 to 10 -hr before the initial discharge of spores. The periodic discharge of conidia under light condition closely resembled that under dark condition in that the conidial discharges occurred after 6 to 10 -hr lag periods on cadavers collected during the day, and the majority

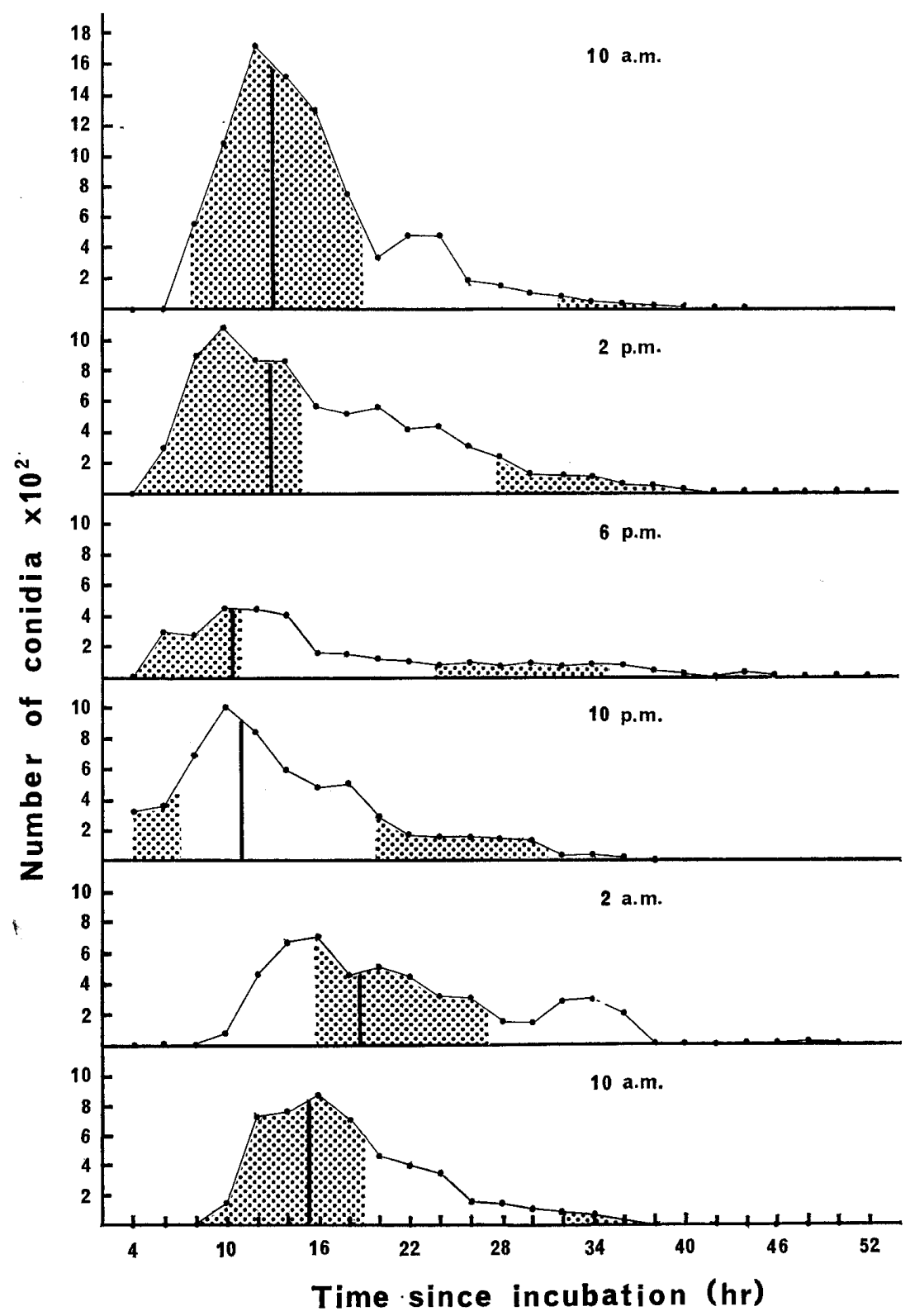

Fig. 3. Patterns of conidial discharges of an Entomophthora species of "grylli" type from infected cadavers of Mamestra brassicae larvae incubated under a continuous light condition at $20^{\circ} \mathrm{C}$. Explanation as in Figure 2. 
of the conidia was discharged at night. On the other hand, the conidial discharges were initiated rapidly within 4 to 6 -hr periods on cadavers collected in the evening and night, and many conidia were already discharged during the night. On cadaver collected at 2 a.m., the initiation of the conidial discharge was delayed and many conidia were discharged the following night. No significant differences were observed in the periodic discharge of conidia under dark and light conditions.

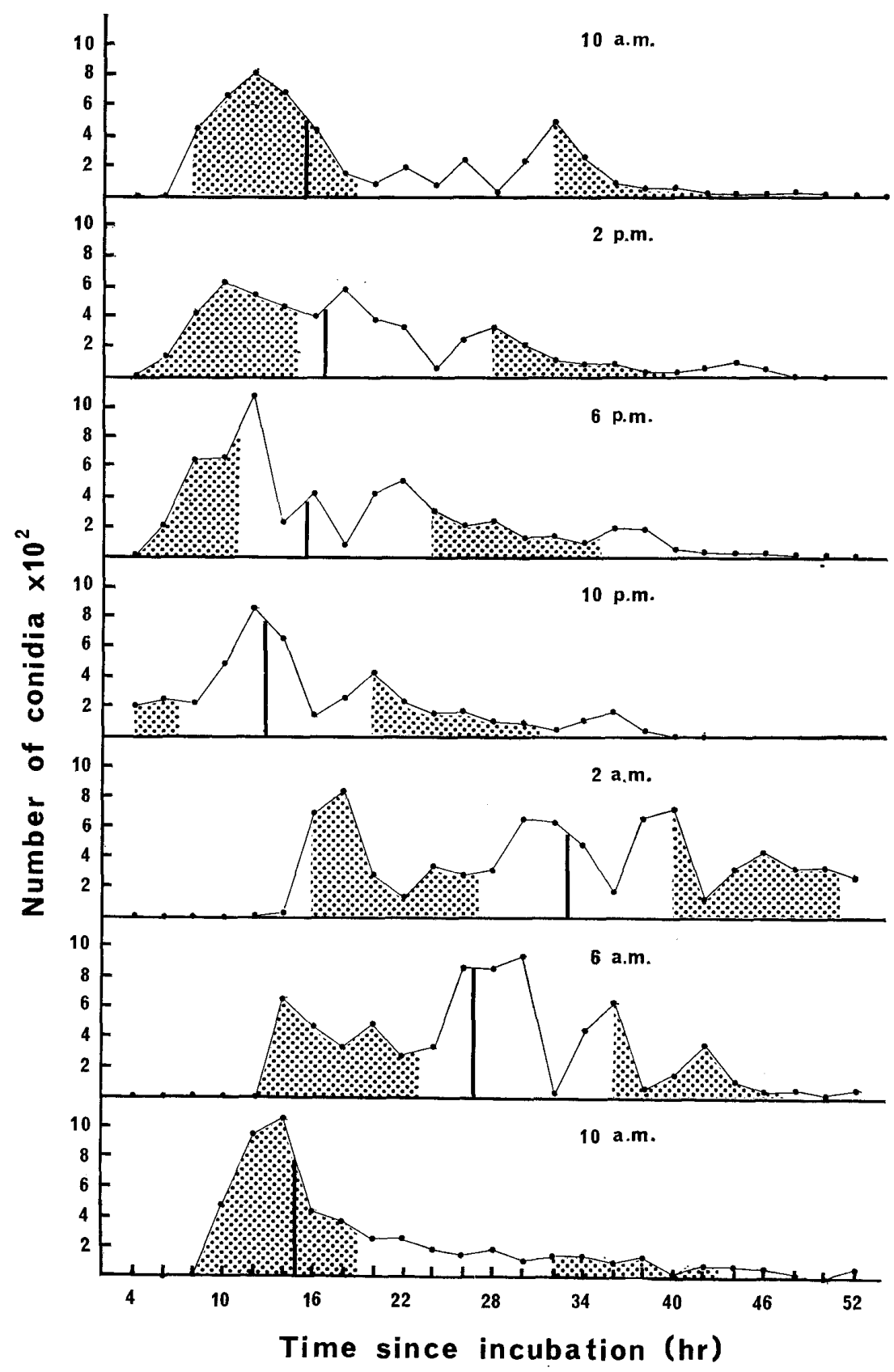

Fig. 4. Patterns of conidial discharges of an Entomophthora species of "grylli" type from infected cadavers of Mamestra brassicae larvae incubated under field conditions. Explanation as in Figure 2. 
Conidial discharge under field condition

The periodic discharges of conidia in all treatments under natural field condition are given in Fig. 4. The periodic patterns of conidial discharges differed markedly from those of the previous two experimental conditions. Under field condition, the conidial discharge had long lag periods especially those from cadavers collected at 2 and $6 \mathrm{a} . \mathrm{m}$. In every case, there were sharp fluctuations and the times of the conidial discharge were prolonged, even into the second night.

Temperature fluctuations in the field were as follows : av. $19.5^{\circ} \mathrm{C}, \max .22 .0^{\circ} \mathrm{C}$ at 2 p.m., min. $18.0^{\circ} \mathrm{G}$ at 10 p.m. in the lst day $\left(10\right.$ a.m. to 10 p.m. ) ; av. $17.0^{\circ} \mathrm{G}$, $\max .25 .0^{\circ} \mathrm{C}$ at $>1$ p.m., min. $13.0^{\circ} \mathrm{C}$ at 6 a.m. in the 2 nd day ( $>1$ a.m. to 10 p.m.) ; av. $20.0^{\circ} \mathrm{C}, \max .28 .0^{\circ} \mathrm{C}$ at $>1$ p.m., min. $16.0^{\circ} \mathrm{C}$ at 4 a.m. in the $3 \mathrm{rd}$ day $(>1 \mathrm{a} . \mathrm{m}$. to 10 p.m.) ; av. $17.1^{\circ} \mathrm{G}, \max .18 .0^{\circ} \mathrm{G}$ at 2 p.m., min. $16.5^{\circ} \mathrm{G}$ at 6 a.m. in the 4 th day (>1 a.m. to 2 p.m.).

Even though there were sharp fluctuations with prolonged conidial discharge period under field condition, the pattern of the conidial discharge during the day was similar to those of the light and dark conditions.

\section{DISGUSSION}

Entomophthora sp. ("grylli" type) is known to attack several species of Noctuidae (Kushida et al., 1975). Recently, HAMm (1980) reported that Entomophthora aulicae caused epizootics in some species of Noctuidae in the Southeastern United States. E. aulicae is usually observed in populations of Lymantria dispar in Japan (AokI, 1974), but is distinctly different from Entomophthora sp. ("grylli" type) whose morphological characters are more similar to those of Entomophthora grylli than to those of E. aulicae according to the descriptions by MACLEOD and MüLler-Kögler (1973).

Many insect species infected with entomophthorous fungi tend to seek elevated positions and crawl upward on blades of grass or other food plants just before dying from the infection. This insect behavior makes it possible for the conidia to be discharged over a considerable area (Steinhaus, 1949). Skaife (1925) reports that the great majority of the red locust, Cyrtacanthacris septemfasciata infected with E. grylli climb to the tops of grass stems and die in the late afternoon, generally somewhere between 3 and 7 p.m. The fungus discharges its conidia generally in the evening, when the locusts are clustered together for the night. Dustan (1923) has found that the green apple bug, Lygus communis var. novascotiensis infected with Entomophthora erupta always bursts open at night or very early in the morning and the spores are discharged while the dew is still on the leaves. In a similar way, most $M$. brassicae larvae infected with E. "grylli" type climb to the upper portions of the carrot leaves just before dying in the afternoon in spite of their nocturnal habit. Furthermore, the fungi in these cadavers discharged their conidia mostly during the night. A few infected larvae died under similar situations at night, but even in this case, the fungi discharged many conidia during the night and appeared to have adjusted the lag period. Such an adjustment would favor the infection and dispersion of the causal fungus in the population of nocturnal insects.

It seems to be a general characteristic that species of Entomophthora produce and discharge conidia in the presence of sufficient moisture (Steinhaus, 1949). In a preliminary test conducted in advance of this investigation, Entomophthora sp. ("grylli" 
type) discharged sparingly its conidia under dry condition. Accordingly, all of the experiments were carried out under same humid condition. Therefore, humidity had no relation to the inherent patterns of the conidial discharges in a day.

The effects of light and dark on the formation and discharge of the conidia of entomophthorous fungi had been observed by several researcheres with in vitro cultures. The conidial formation of the fly parasite, Entomophthora muscae was stimulated by light (Schweizer, 1948). Other Entomophthorales fungi, Conidiobolus rhysosporus (Dring, 1958), Conidiobolus coronatus and Basidiobolus ranarum (Callaghan, 1969) also produced conidia more abundantly in the light than in the dark. On the other hand, Entomophthora sphaerosperma and Entomophthora sp. which were isolated respectively from Rhopobota vacciniana and Peronea minuta produced conidia equally well in total darkness as in light (SAwYER, 1929). Normally, Entomophthora pseudococci isolated from the mealy bug, Pseudococcus calceolariae discharged its spores at night, and only occasionally and sparingly in the daytime (SPEARE, 1912). On the other hand, C. coronatus, Entomophthora planchoniana, and Entomophthora virulenta which were isolated from aphid, such as Aphis fabae and others, discharged a great number of conidia in continuous light, and a smaller number in the dark (EGE, 1965). Furthermore, the transfer of $C$. coronatus and B. ranarum from dark to light conditions stimulated spore discharge (Gallaghan, 1969). PAge (1965) reported that the conidia of Conidiobolus, Entomophthora, and Basidiobolus were discharged toward the light.

In the present study, the pattern of the conidial discharge by Entomophthora sp. ("grylli" type) was similar to that of E. pseudococci. There was no doubt that the conidia of Entomophthora sp. ("grylli" type) were discharged from the cadavers of M. brassicae larvae mostly during the night in the field. However, there were no differences in the pattern of the conidial discharge when the infected cadavers were incubated under dark and light conditions. Therefore, the light or dark condition may affect the pre sporulation development of the fungus. The longest lag period occurred in the cadavers collected at 2 a.m. and held under all treatments. The length of the lag period decreased gradually with cadavers collected after 2 a.m. and was minimal at 10 p.m. In E. pseudococci, SpeARE (1912) observed that one of the young conidiophores remained absolutely dormant from 8 a.m. until about 3 p.m., while the other conidiophores grew only slowly at their tips. At 3 p.m., all of the conidiophores began to grow vigorously to form conidia at night. If the same situation occur in the present investigation, this may explain the changes in the lag period of Entomophthora sp. ("grylli" type).

In general, the number of discharged conidia decreased in the afternoon and the fewest number was obtained at 6 p.m. regardless of whether the cadavers had been incubated at $20^{\circ} \mathrm{G}$ under dark or light conditions. On the other hand, the fewest number of conidial discharge occurred at 2 p.m. when the cadavers were held under natural field condition. The time differences under the two conditions seemed to be caused by temperature variations. There was a subsequent increase in the conidial discharge under both of these conditions. These results support the existence of a mechanism to break the dormancy in sporulation that occurs in the late afternoon. The marked differences in time lag between cadavers collected at 10 p.m. and 2 a.m. together with the extraordinarily irregular pattern of the conidial discharge at 2 a.m. suggest that the dormancy in sporulation begins between 10 p.m. and 2 a.m. The hypothesis on the dormancy of the fungus needs to be substantiated 
in future studies based on morphological observations of the fungal growth in the infected host. There is an interesting question of the basis for the infected larva to climb to elevated portions of plants and to die generally at the time when the dormancy is broken. The answer to this question on larval behavior is very important in the analysis of fungal dispersal in entomophthorous epizootics of insect populations.

Entomophthora sp. ("grylli" type) had been found on 16 different species of Lepidoptera (MAGLEOD, 1956), however, the pattern of the conidial discharge on unnocturnal insects is still unknown. Therefore, there is a need for more information on the conidial discharge on such species.

\section{AGKNOWLEDGEMENTS}

I wish to thank Mr. A. Ohkawa, H. Kawamoto, M. Koda, A. NitTa, and Y. Tsukidate who were students in the Department of Plant Protection, Tokyo University of Agriculture and Technology, for their help during the experiments, and Mrs. K. Mogam for preparing the figures. I also wish to thank Professor Y. TANAdA, Division of Entomology and Parasitology, University of California, Berkeley, for reviewing the manuscript.

\section{REFERENCES}

Aoki, J. (1974) Mixed infection of the gypsy moth, Lymantria dispar Japonica Motschulsky (Lepidoptera : Lymantriidae), in a larch forest by Entomophthora aulicae (REICH.) Sorok. and Paecilomyces canadensis (Vuill.) Brown et Smith. Appl. Ent. Zool. 9 : 185-190.

Callaghan, A. A. (1969) Light and spore discharge in Entomophthorales. Trans. Br. Mycol. Soc. 53 : 87-97.

Dring, V. G. (1958) Conidiobolus rhysosporus Dresahler in Great Britain. Trans. Br. Mycol. Soc. 41 : $52-54$.

Dustan, A. G. (1924) Studies on a new species of Empusa parasitic on the green apple bug (Lygus communis var. novascotiensis KNIGHT) in the Annapolis valley. Proc. Acad. Entomol. Soc. No. 9 : 14-36.

EGE, O. (1965) Ein Beitrag zur Biologie einiger aphidivorer Entomophthoraceen. Arch. Mikrobiol. $52: 20-48$.

НАмм, J. J. (1980) Epizootics of Entomophthora aulicae in Lepidopterous pests of sorghum. J. Invertebr. Pathol. $36: 60-63$.

Kushida, T., K. Katagiri and J. Aokr (1975) Infection of Aedia leucomelas L. (Lepidoptera : Noctuidae) by an Entomophthora species of the "grylli" type in Japan. Appl. Ent. Zool. $10: 226-230$.

MagLeod, D. M. (1956) Notes on the genus Empusa Cohn. Can. J. Botany 34 : 16-26.

MAcLeOd, D. M. and E. MüLler-Kögler (1973) Entomogenous fungi : Entomophthora species with pearshaped to almost spherical conidia (Entomophthorales : Entomophthoraceae) Mycologia 65 : 823-893.

PAGE, R. M. (1965) The physical environment for fungal growth : 3. Light. In : The fungi : I. The fungal cell. (Ainsworth, G. G. and A. S. Sussman eds.), New York and London : Academic Press, pp. 559574.

SAWYER, W. H. (1929) Observations on some entomogenous members of the Entomophthoraceae in artificial culture. Am. J. Botany $16: 87-121$.

Schweizer, G. (1947) Über die Kultur von Empusa muscae CoHn und anderen Entomophthoraceen auf kalt sterilisierten Nährböden. Planta 35 : 132-176.

Skaife, S. H. (1925) The locust fungus, Empusa grylli, and its effects on its host. S. African J. Sci. 22 : 298-308.

Speare, A. T. (1912) Fungi parasitic upon insects injurious to sugar cane. Bull. Hawaiian Sugar Planters' Assoc. Exp. Sta., Ser. Pathol. Physiol. No. 12 : 7-62.

Steinhaus, E. A. (1949) Principles of insect pathology. New York, Toronto, and London : McGraw-Hill, 757 p. 